\title{
A high-throughput screening identifies histone deacetylase inhibitors as therapeutic agents against medulloblastoma
}

\author{
Shanshan Zhang ${ }^{1,2,3 \dagger}{ }^{\dagger}$, Zhaojian Gong ${ }^{2,4 \dagger}$, Peter O. Oladimeji ${ }^{5 \dagger}$, Duane G. Currier ${ }^{5}$, Qipan Deng ${ }^{1,2}$, Ming Liu,
} Taosheng Chen ${ }^{5^{*}}$ and Yong $\mathrm{Li}^{1,2^{*}}$ (1)

\begin{abstract}
Background: Medulloblastoma is the most frequently occurring malignant brain tumor in children. Current treatment strategies for medulloblastoma include aggressive surgery, cranio-spinal irradiation and adjuvant chemotherapy. Because current treatments can cause severe long-term side effects and are not curative, successful treatment remains a challenge.

Methods: In this study, we employed a high-throughput cell viability assay to screen 12,800 compounds and to identify drug candidates with anti-proliferative properties for medulloblastoma cells. We also tested these compounds for attenuating medulloblastoma tumor development using mouse xenografts.

Results: We identified two histone deacetylase inhibitors (dacinostat and quisinostat) with anti-proliferative properties for medulloblastoma cells. We showed that both compounds induce cytotoxicity, trigger cell apoptosis, and block cell cycle progression at the G2/M phase. In addition, dacinostat and quisinostat attenuated xenograft medulloblastoma growth in mice.
\end{abstract}

Conclusions: Our findings suggest that histone deacetylase inhibitors are potent therapeutic agents against medulloblastoma.

Keywords: High-throughput screening, Medulloblastoma, HDAC inhibitors, Dacinostat, Quisinostat

\section{Introduction}

Medulloblastoma is the most common malignant pediatric brain tumor, accounting for nearly $20 \%$ of all childhood central nervous system malignancies [1]. More than $80 \%$ of medulloblastoma are diagnosed in children who are younger than 15 years of age. At least four distinct subtypes comprise medulloblastoma: WNT-activated, SHH-activated, non-WNT/non-SHH group 3, and non-WNT/non-SHH group 4, with group 3 patients

\footnotetext{
*Correspondence: taosheng.chen@stjude.org; yong.li@bcm.edu †Shanshan Zhang, Zhaojian Gong and Peter O. Oladimeji contributed equally to this work

${ }^{1}$ Section of Epidemiology \& Population Sciences, Department of Medicine, Baylor College of Medicine, Houston, TX, USA

${ }^{5}$ Department of Chemical Biology and Therapeutics, St. Jude Children's

Research Hospital, Memphis, TN, USA

Full list of author information is available at the end of the article
}

carrying c-Myc overexpression having the worst prognosis, as reflected in the current revision of the WHO classification [2-5]. Current treatment strategies for medulloblastoma include aggressive surgery, craniospinal irradiation, and adjuvant chemotherapy, with the strategy chosen depending on whether disease is highrisk or low-risk. Successful treatment of medulloblastoma remains a challenge in many patients. Although the 5-year overall survival rate for children with average-risk disease is $70 \%$ to $80 \%$, most patients suffer from therapy-related side effects [6]. New treatment strategies are needed that improve patient survival and have fewer adverse effects.

Histone deacetylases (HDACs) are critical epigenetic regulators that have been implicated in oncogenesis because they can silence tumor suppressor genes and genes that induce apoptosis $[7,8]$. As HDACs are 
frequently upregulated in cancers, they represent potential therapeutic targets. HDAC inhibitors are a promising group of anti-cancer drugs that change the gene expression patterns of cancer cells by epigenetic modulation. In this study, we performed a high-throughput drug screening to identify compounds that inhibit medulloblastoma growth and tumorigenesis. We found that two HDAC inhibitors, dacinostat and quisinostat, are superior to other compounds in elevating medulloblastoma apoptosis and attenuating tumor growth. Strikingly, both compounds reduced the expression of c-Myc. Given that HDAC expression has been reported to be upregulated in medulloblastoma [9], these data suggest that HDAC inhibitors are a new strategy to treat this devastating malignancy, particularly group 3 disease with c-Myc overexpression.

\section{Materials and methods}

\section{Cell lines}

The human medulloblastoma cell lines Daoy and D283 were obtained from the American Type Culture Collection (ATCC, Manassas, VA) and cultured in Eagle's Minimum Essential Medium (MEM) containing 10\% fetal bovine serum (Thermofisher, Waltham, MA). Mycoplasma testing was conducted every 3 months to ensure no contamination. All cells were maintained in a humidified incubator at $37^{\circ} \mathrm{C}$ and $5 \% \mathrm{CO}_{2}$. For all studies, medulloblastoma cells were grown to $50-70 \%$ confluence on $10-\mathrm{cm}$ plates and then treated with dacinostat and quisinostat for the indicated time periods. All methods related to human cells were carried out in accordance with National Institutes of Health (NIH) guidelines and regulations and Cleveland Clinic Institutional Biosafety Committee polices.

\section{Compound screening}

We developed a cytotoxicity assay using the CellTiter-Glo Luminescent Cell Viability Assay (Promega, Madison, WI) to screen a bioactive compound library (including FDA-approved drugs) $[10,11]$ for compounds that inhibit the growth of Daoy cells. Cells were plated at 3000 cells/well in 384-well tissue culture plates. Compounds were added $(10 \mu \mathrm{M}$ for the primary screen and 10 different concentrations as indicated in the dose-response analysis), and cells were incubated at $37^{\circ} \mathrm{C}$ and $5 \% \mathrm{CO}_{2}$ for $48 \mathrm{~h}$. Vehicle (dimethyl sulfoxide [DMSO]: $0.1 \%$ for primary screen and $0.5 \%$ for dose-response analysis) and staurosporine $(10 \mu \mathrm{M})$ were used as negative $(0 \%$ inhibition) and positive (100\% inhibition) controls, respectively. From the primary screen of 12,800 compounds, we selected 125 compounds that displayed $\geq 90 \%$ inhibition for dose-response analysis (10 concentrations, 1:3 serially diluted: $0.0025,0.0076,0.023,0.068,0.2,0.6,1.9,5.6$, 16.7 , and $50 \mu \mathrm{M})$. Of the 125 tested, 113 compounds were confirmed to inhibit cell growth in a dose-responsive manner. Examples include pitavastatin, which has an $\mathrm{IC}_{50}$ value of $84 \mathrm{nM}$. The general screening process and data analysis have been previously described [12-15].

\section{Chemical compounds}

Dacinostat and quisinostat were obtained from MedChemExpress LLC (Princeton, NJ). These two compounds were dissolved in DMSO $(10 \mathrm{mM} / \mathrm{mL})$ before diluted with phosphate-buffered saline (PBS) to treat cells or mice.

\section{Cell viability assay}

Medulloblastoma cells were seeded in sextuplicate in 96-well plates and treated for $48 \mathrm{~h}$ with dacinostat and quisinostat $(0,0.0025,0.0076,0.023,0.068,0.2,0.6,1.9$, $5.6,16.7$, or $50 \mu \mathrm{M})$. Viability was measured using the MTT Cell Proliferation Assay Kit (ATCC, Manassas, VA).

\section{Apoptosis and cell cycle distribution assessment}

Medulloblastoma cells were incubated with dacinostat or quisinostat at their $\mathrm{IC}_{50}$ concentration for $24 \mathrm{~h}$ and $48 \mathrm{~h}$. After incubation, floating and adherent cells were collected, washed with serum-free medium, and suspended in PBS. The cell suspension was stained with FITCconjugated annexin $\mathrm{V}$ and propidium iodide (PI) using the Alexa Fluor 488 annexin V/Dead Cell Apoptosis Kit (Thermofisher) and then analyzed by flow cytometry. Cell apoptosis and cell cycle distribution analyses were performed using FlowJo (FlowJo LLC, Ashland, OR).

\section{Protein extracts and Western blotting analysis}

After incubating Daoy and D283 cells with dacinostat or quisinostat for the indicated amount of time, cells were collected and washed with PBS. Cells were lysed with RIPA lysis buffer containing protease and phosphatase inhibitors to extract the soluble cellular proteins. The lysates were boiled for $5 \mathrm{~min}$ at $95^{\circ} \mathrm{C}$. Protein concentration was measured with the BCA protein assay reagent (Pierce, Rockford, IL, USA). The samples were diluted with lysis buffer containing $20 \mathrm{mM}$ dithiothreitol, and equal amounts of protein were loaded on $10 \%$ to $15 \%$ SDS-polyacrylamide gels (Mini-PROTEAN TGX Precast gels, Bio-Rad, Hercules, CA), separated, and transferred onto polyvinylidene difluoride (PVDF) membranes. The membrane was blocked with $5 \%$ nonfat dry milk in Tris-buffered saline (TBS) containing 0.1\% Tween-20 (v/v) for $1 \mathrm{~h}$ and incubated with primary antibody at $4{ }^{\circ} \mathrm{C}$ overnight. The primary antibodies were purchased from Cell Signaling Technology (Danvers, MA, USA): caspase-3 (\#9662), cleaved-caspase-3 (\#9661), cleaved-PARP (\#5625), Acetyl-Histone H3 (\#8173), acetyl-histone H4 (\#13944), and $\beta$-actin (\#3700). Horseradish peroxidaseconjugated anti-rabbit or anti-mouse IgG was used as the secondary antibody. Immunoreactive proteins were 
visualized with the Pierce ECL Western blotting substrate, according to the provided protocol. Blots were quantified by scanning densitometry using area integration.

\section{Animal models}

Human medulloblastoma Daoy xenograft tumors were established by subcutaneously injecting $2 \times 10^{6}$ cells suspended in $100 \mu \mathrm{m}$ PBS into the right flank of 6-weekold male NSG mice (Jackson, MA, USA). Tumors were measured every 3 days using calipers. Tumor volume was calculated as width $\times$ length $\times$ height $\times 0.52$. When tumor volumes reached $100 \mathrm{~mm}^{3}$, treatment was administered by intraperitoneal injection every 2 days. Mice were randomized into four treatment groups $(n=5$ per group). Both dacinostat and quisinostat diluted in PBS were administered at $20 \mathrm{mg} / \mathrm{kg}$ body weight. DMSO diluted in proper volume of PBS was used as the vehicle control. Mice were fed ad libitum and maintained in environments with a controlled temperature of $\sim 22{ }^{\circ} \mathrm{C}$ and $12 \mathrm{~h}$ light and dark cycles. After 18 days of treatment, animals were sacrificed, and tumors were excised and analyzed. All procedures involving animals were carried out in accordance with $\mathrm{NIH}$ guidelines and regulations, and experimental protocols were approved by our Institutional Animal Care and Use Committee.

\section{Histology and immunohistochemical analyses}

For each subcutaneous tumor, $4-\mu \mathrm{m}$ thick paraffin sections were prepared and stained with hematoxylin and eosin. Immunohistochemistry of Ki-67 and cleaved PARP was performed by the Human Tissue Acquisition and Pathology Core at Baylor College of Medicine. Images from sections were recorded with an Olympus microscope and advanced image acquisition software (version 1.13, cellSens Dimension).

\section{Statistical analysis}

Significant differences between the vehicle controls versus treatment groups were determined by an unpaired two-sided t-test. Statistical analysis was carried out using GraphPad InStat 7 software (GraphPad Software, Inc., San Diego, CA, USA). $\mathrm{P} \leq 0.05$ was considered statistically significant.

\section{Results}

\section{High-throughput screening identified dacinostat} and quisinostat

In our high-throughput screen, we employed the CellTiter-Glo Luminescent Cell Viability Assay, a homogeneous method of measuring the number of viable cells based on quantitation of ATP, which is an indicator of metabolically active cells. We incubated Daoy cells with each compound at a final concentration $10 \mu \mathrm{M}$ for $48 \mathrm{~h}$.
From 12,800 compounds screened, we selected 125 compounds that displayed $\geq 90 \%$ inhibition for further analysis in dose responsive manner (10 concentrations, 1:3 serially diluted ranging from 50 to $0.0025 \mu \mathrm{M}$ in triplicate) (see Additional file 1: Data S1 and Additional file 2: Figure S1). The $Z^{\prime}$-factor, which was used to assess assay performance [16], ranged from 0.50 to 0.85 , with an average value of 0.72 (Additional file 2: Figure S1B). We found 113 compounds that inhibited cell growth in a dose-responsive manner with an $\mathrm{IC}_{50}$ of $\leq 10 \mu \mathrm{M}$ at $48 \mathrm{~h}$ of incubation. Among them, 46 compounds had an $\mathrm{IC}_{50}$ of $\leq 1 \mu \mathrm{M}$ (Fig. 1 and Additional file 1: Data S1). Next, we shortened this list to 7 compounds based on the following criteria: (1) low reported toxicity; (2) $\mathrm{IC}_{50} \leq 100 \mathrm{nM}$ (Additional file 1: Data S1).

To minimize false positives, we ordered 6 of these 7 compounds (EVP4593 is not commercially available) in powder form and tested their activities in another medulloblastoma cell line $\mathrm{D} 283$. We determined the $\mathrm{IC}_{50}$ values of these 6 compounds against D283 cells. Three compounds quisinostat, dacinostat, and proscillaridin A had $\mathrm{IC}_{50}<200 \mathrm{nM}$ for D283 cells. Proscillaridin is a cardiac glycoside, a drug used to treat congestive heart failure and cardiac arrhythmia. As both quisinostat and dacinostat are inhibitors to HDACs (Fig. 1b, c), we chose them for follow-up studies.

\section{Dacinostat and quisinostat induce apoptosis in medulloblastoma cells}

We investigated whether dacinostat and quisinostat induced apoptosis in medulloblastoma cells. Both dacinostat and quisinostat treatment resulted in a higher percentage of apoptotic cells, when compared with vehicle group, in a time-dependent manner (Fig. 2a-d). At 48 h, the percentage of apoptotic cells upon treatment with dacinostat increased 24\% in Daoy cells and 14\% in D283 cells, respectively (Fig. 2c). The percentage of apoptotic cells upon treatment with quisinostat increased $42 \%$ in Daoy and 50\% in D283, respectively (Fig. 2d). These results suggest that apoptosis induction contributes to the reduced cell viability of both Daoy and D283 cells treated with dacinostat and quisinostat. We next examined the expression of poly-ADP ribose polymerase (PARP) and caspase-3. In treated Daoy and D283 cells, caspase-3 decreased, whereas cleaved caspase- 3 and cleaved PARP increased (Fig. 2e, f). These results indicate the increased apoptosis in medulloblastoma cells treated with HDAC inhibitors is mediated by caspase activation.

\section{Dacinostat and quisinostat induced G2/M arrest of medulloblastoma cells}

To further characterize the cytotoxic efficacy of dacinostat and quisinostat, we analyzed cell cycle 


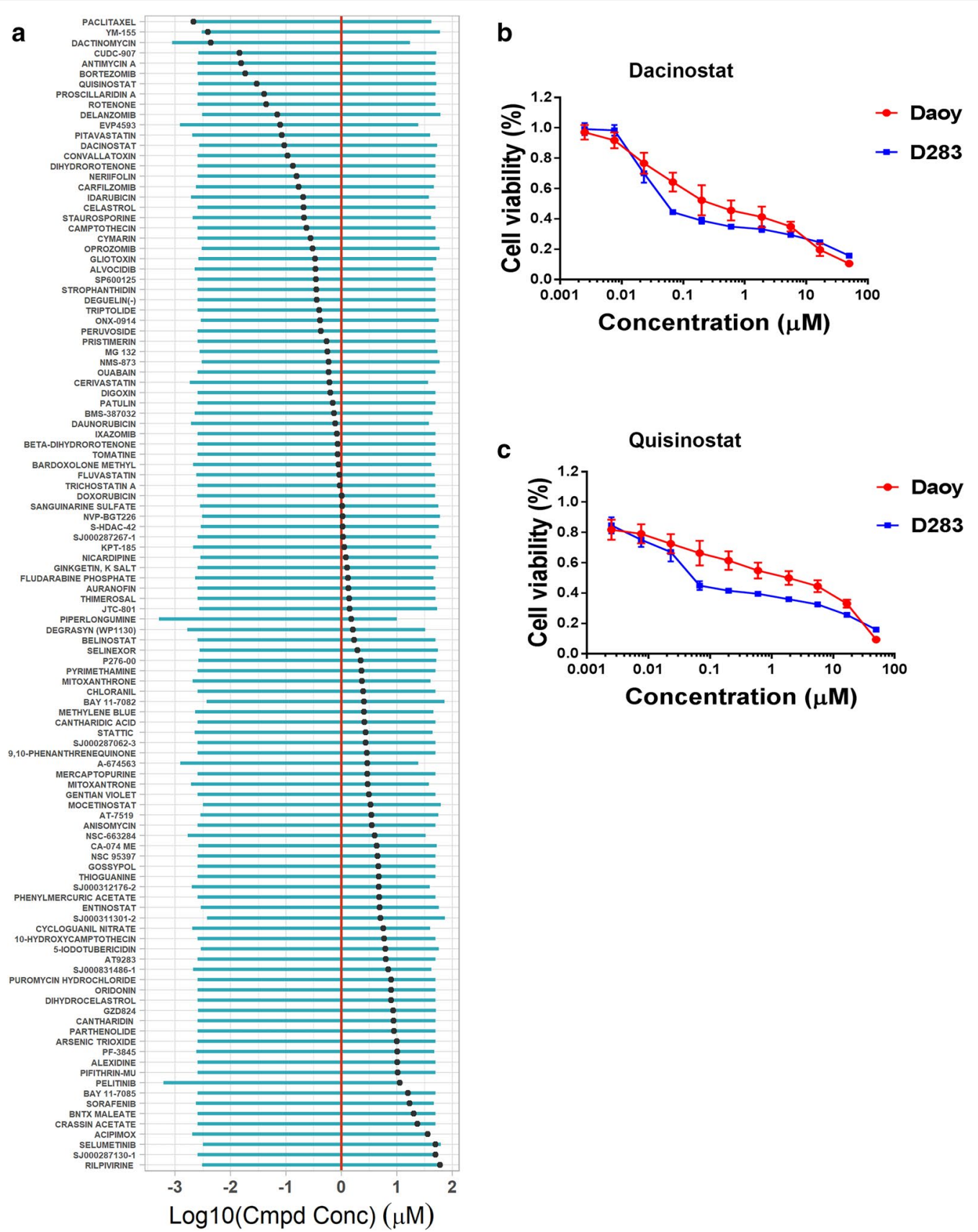

Fig. 1 High-throughput screen identifies dacinostat and quisinostat that reduce cell viability of Daoy and D283 cells. a 125 compounds were assayed for their $I C_{50}$ values after the screening of 12,800 compounds. Blue bars represent the concentration range interrogated and black points indicate the $\mathrm{IC}_{50}$ value derived from the curve fit. The red line represents the $1 \mu \mathrm{MI} \mathrm{IC}_{50}$ cutoff used to identify the 46 most potent compounds. Compounds having names too long to fit on the plot axis are identified by their compound identifier; their names are as follows: SJ000831486-1 = BML285 (diaminoquinazoline); SJ000287267-1 = cephaeline dihydrochloride heptahydrate; SJ000311301-2 =NA; SJ000312176-2 = aurora kinase/CDK inhibitor; SJ000287062-3= 1-benzyloxycarbonylaminophenethyl chloromethyl ketone; SJ000287130-1 = lysyltryptophanyl-lysine acetate. Cmpd Conc, compound concentration. b, c The dose response curves (based on MTT assays) for cell viability of Daoy and D283 cells after treated with dacinostat and quisinostat for $48 \mathrm{~h}$ at the indicated concentrations

progression. Daoy and D283 cells were treated with dacinostat $(0.1 \mu \mathrm{M}$ for Daoy, $0.01 \mu \mathrm{M}$ for D283 cells) and quisinostat $(0.4 \mu \mathrm{M}$ for Daoy cells, $0.04 \mu \mathrm{M}$ for D283 cells) for $24 \mathrm{~h}$ and $48 \mathrm{~h}$, subjected them to flow cytometry (Fig. 3a, b), and then determined the percentage of cells in each phase (Fig. 3c-f). The percentage of cells in 
a

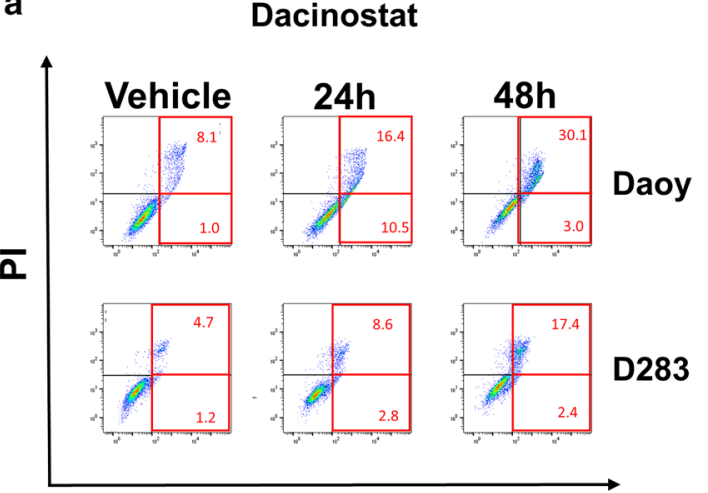

Annexin V-FITC

C

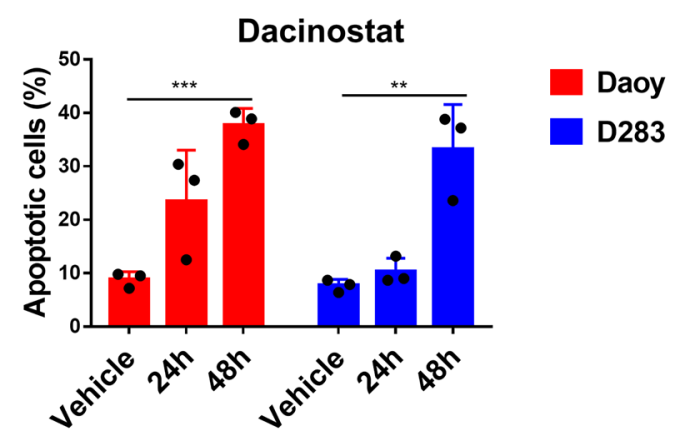

DAOY

e

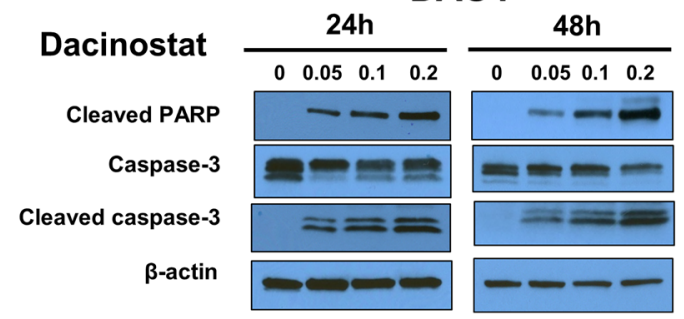

DAOY

f

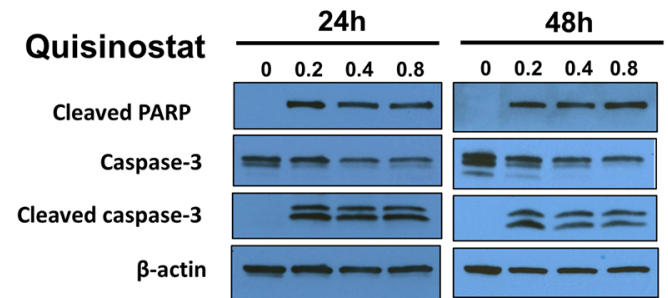

b

\section{Quisinostat}

$\bar{a}$

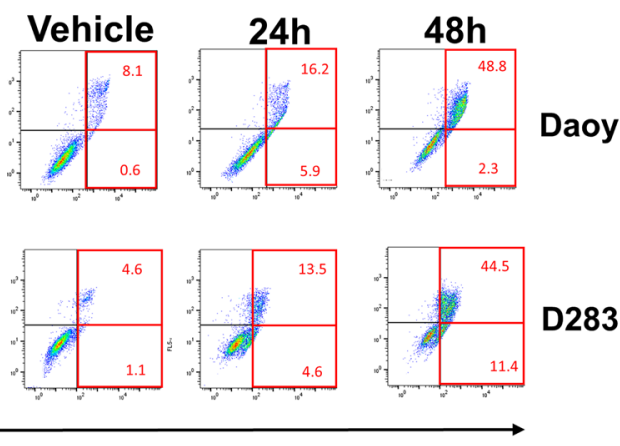

Annexin V-FITC

d

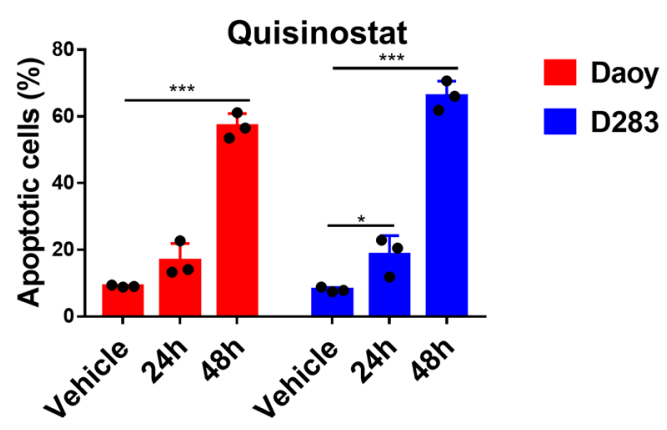

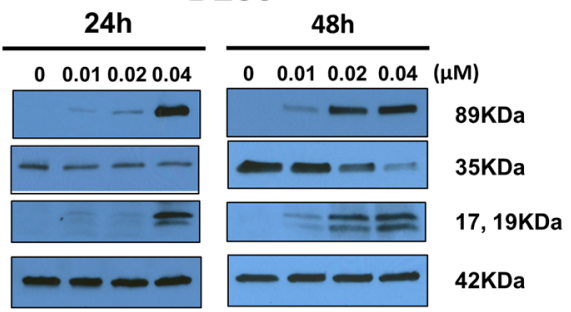

\section{D283}

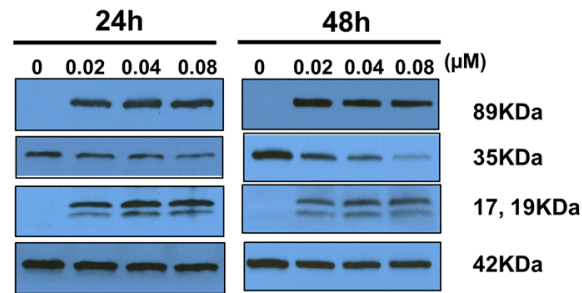

Fig. 2 Dacinostat and quisinostat increase apoptosis of Daoy and D283 cells. a, b Daoy and D283 cells were treated with dacinostat $(0.1 \mu \mathrm{M}$ for Daoy cells, $0.01 \mu \mathrm{M}$ for D283 cells) or quisinostat ( $0.4 \mu \mathrm{M}$ for Daoy cells, $0.04 \mu \mathrm{M}$ for D283 cells) for $24 \mathrm{~h}$ and $48 \mathrm{~h}$, respectively. Apoptosis was analyzed with flow cytometry. Experiments were performed three times with one representative scatterplot shown. $\mathbf{c}$, $\mathbf{d}$ Percentage of apoptotic cells. An unpaired t test was performed to compare each treatment group with the vehicle control (PBS). ${ }^{*} P \leq 0.05,{ }^{* *} P \leq 0.01,{ }^{* * *} P \leq 0.001$. e, f Dacinostat and quisinostat induce the cleavage of caspase-3 and PARP. Daoy and D283 cells were treated with dacinostat and quisinostat at indicated concentrations for $24 \mathrm{~h}$ and $48 \mathrm{~h}$, respectively. The target protein expression was analyzed by western blot 

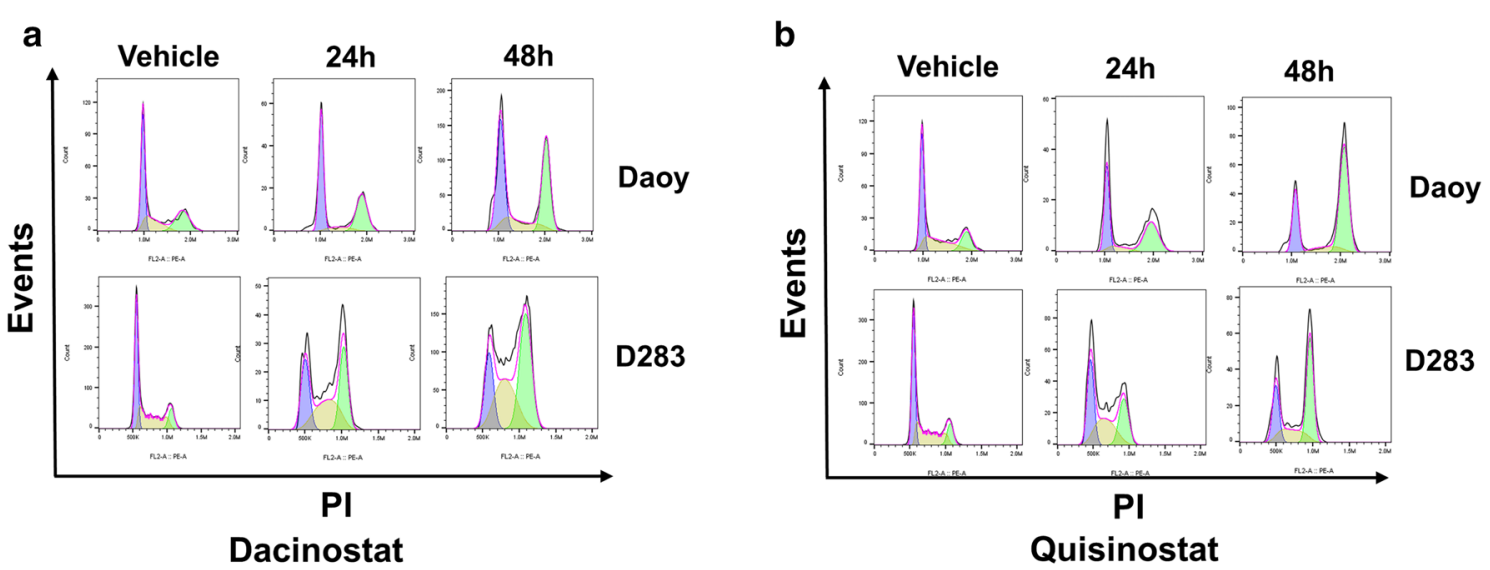

C

Daoy

d

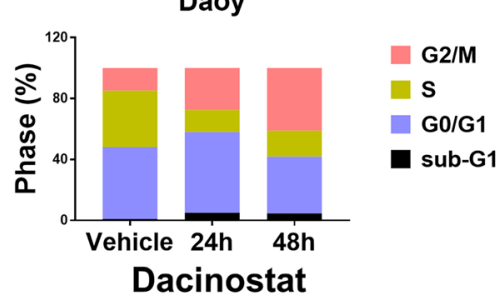

e

D283

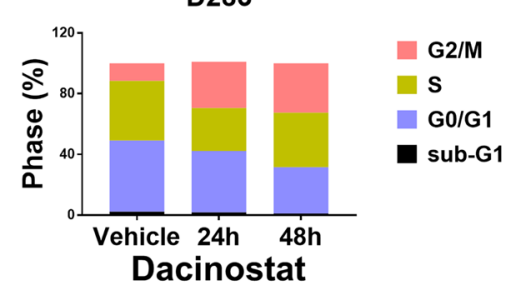

f
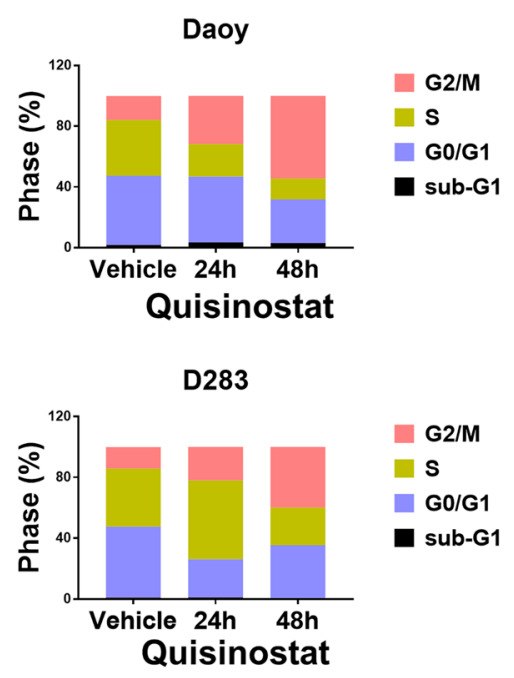

g

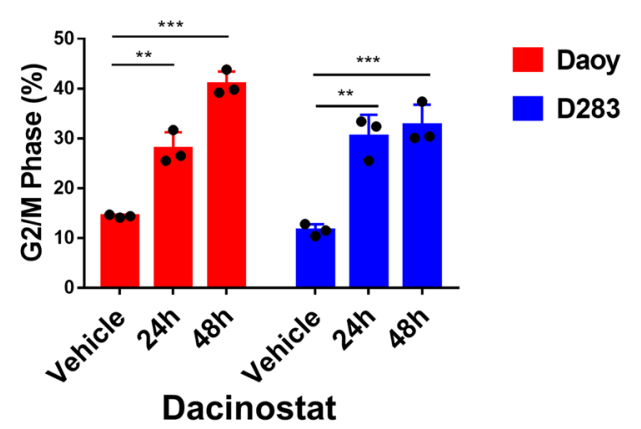

h

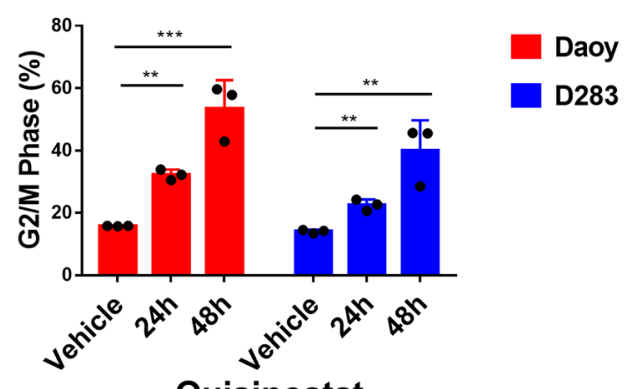

Fig. 3 Dacinostat and quisinostat induce G2/M arrest in Daoy and D283 cells. a, b Daoy and D283 cells were treated with dacinostat (0.1 $\mu M$ for Daoy cells, $0.01 \mu \mathrm{M}$ for D283 cells) or dacinostat ( $0.4 \mu \mathrm{M}$ for Daoy cells, $0.04 \mu \mathrm{M}$ for D283 cells) for $24 \mathrm{~h}$ and $48 \mathrm{~h}$, respectively. The cell cycle distribution was analyzed by flow cytometry using FlowJo. c-f Histograms showing the percentage of Daoy and D283 cells in the subG1, G0-G1, $\mathrm{S}$, and G2/M phases. $\mathbf{g}, \mathbf{h}$ Percentage of cells in the G2/M phase. ${ }^{*} P \leq 0.05,{ }^{*} P \leq 0.01,{ }^{* * *} P \leq 0.001$. Experiments were performed three times, and values were presented as the mean $\pm \mathrm{SE}$

the G2/M phase significantly increased in both cell lines compared with vehicle treatment (Fig. 3g, h). These data indicate that dacinostat and quisinostat induce cell cycle arrest in medulloblastoma cells.
Histone acetylation, Akt, and c-Myc expression

We next performed western blotting analyses to determine histone acetylation and the key cancer pathways associated with HDAC inhibitors (Fig. 4). As expected, 


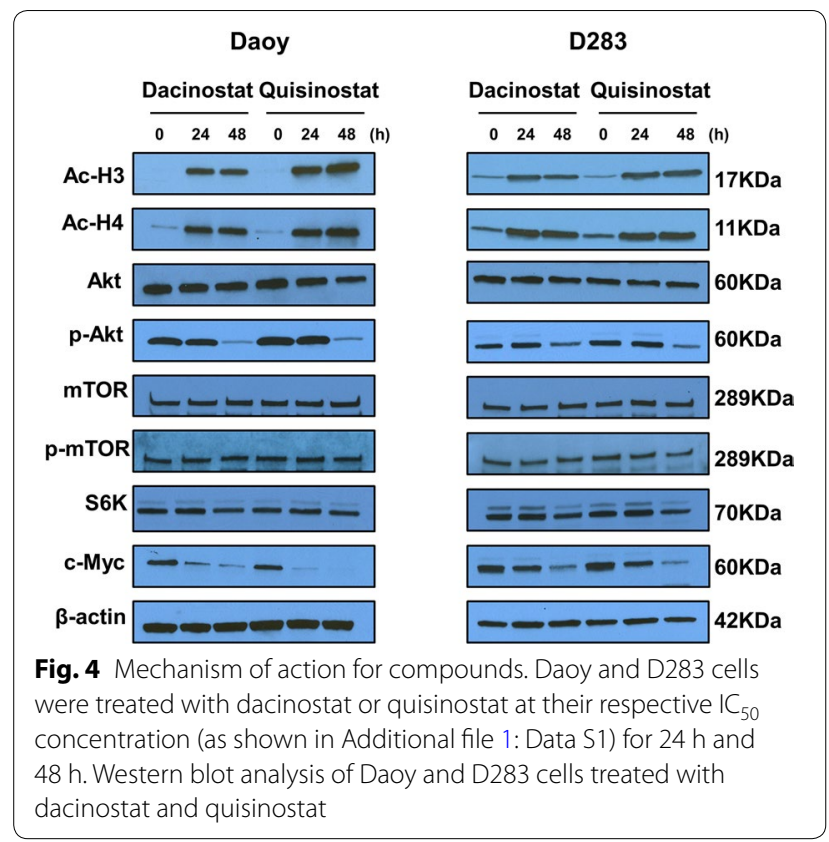

the acetylation for both histones $\mathrm{H} 3$ and $\mathrm{H} 4$ was significantly augmented in treated Daoy and D283 cells. Akt phosphorylation was significantly inhibited at $48 \mathrm{~h}$ posttreatment; however, the phosphorylation of mTOR and the expression of S6K were only marginally affected. In agreement with a previous report that HDAC inhibition reduces c-Myc expression, we found that both dacinostat and quisinostat strikingly reduced the expression of c-Myc in Daoy and D283 cells. These data demonstrate that HDAC inhibition elevates histone acetylation and constrain major cancer signaling pathways such as c-Myc and Akt in medulloblastoma cells.

\section{Dacinostat and quisinostat attenuate Daoy xenograft tumorigenesis}

Finally, we evaluated the in vivo anti-tumor effects of dacinostat and quisinostat on medulloblastoma xenografts. Daoy cells were inoculated subcutaneously into NSG mice, and once tumors were established, mice were injected intraperitoneally with $20 \mathrm{mg} / \mathrm{kg}$ dacinostat or quisinostat every other day. We found that dacinostat or quisinostat treatment suppressed tumor growth significantly (Fig. 5af). Animal body weight was not significantly changed by either treatment (Fig. 5g, h). Moreover, dacinostat and quisinostat treatment notably reduced cell proliferation and increased cell apoptosis, as indicated by fewer Ki67-positive cells and more cleaved PARP-positive cells (Fig. 5i). These data suggest that dacinostat and quisinostat inhibit medulloblastoma tumor cell proliferation, increase apoptosis, and attenuate xenograft tumorigenesis in vivo.

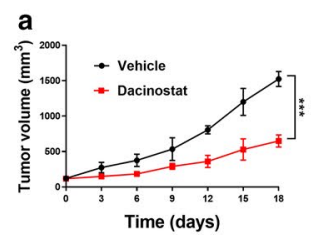

C
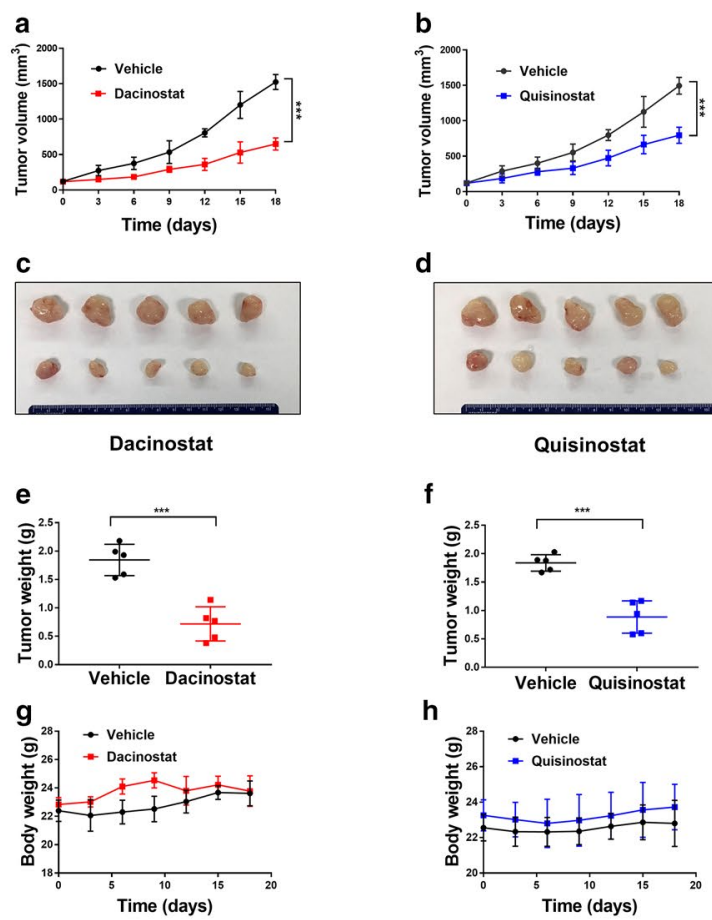

d

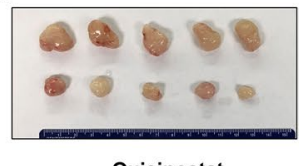

Quisinostat

f

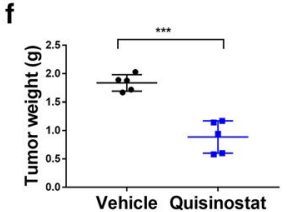

h

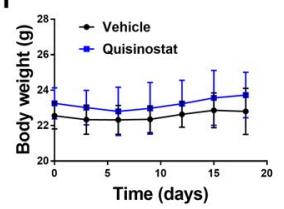

i

i Vehicle
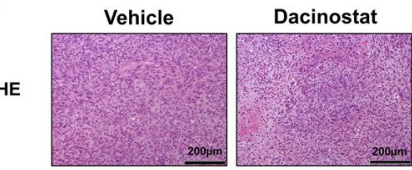

Quisinostat

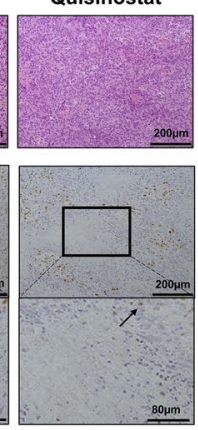

Ki67
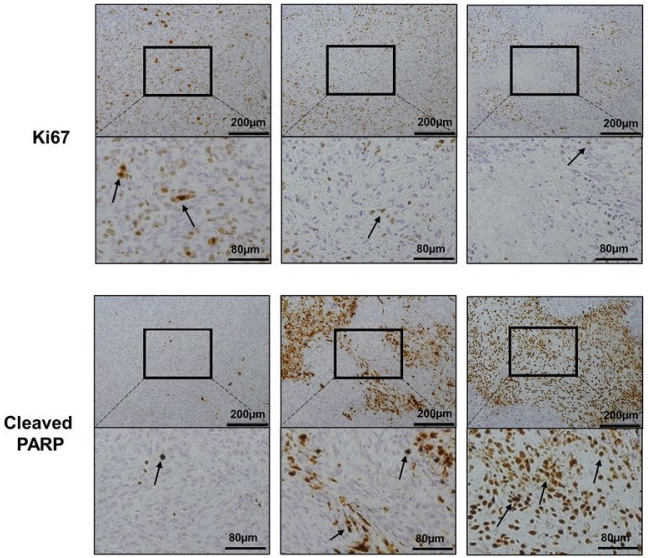

Fig. 5 Dacinostat and quisinostat attenuate tumorigenesis of medulloblastoma xenografts in NSG mice. $\mathbf{a}$, $\mathbf{b}$ Tumor volumes during treatment were measured using calipers. Values were presented as the mean \pm SE. c, d Gross tumors at day 18 post-treatment. e, f Tumor weights at day 18 post-treatment. $\mathbf{g}$, $\mathbf{h}$ Body weight during treatment was measured. Values were presented as the mean \pm SE. i Histological analysis of tumor. Representative images of immunohistochemistry staining for Ki67 and cleaved PARP in tumor tissues were shown. Black arrows pointed to cells with positive staining. HE hematoxylin and eosin staining 


\section{Discussion}

Medulloblastoma represents $12 \%$ of childhood brain tumors. Recent advances in cancer genetics and genomics have classified medulloblastoma into four molecular subgroups: WNT, SHH, group 3 (c-Myc overexpression), and group 4. Among them, group 3 patients have the poorest prognosis, as the majority of cases are metastatic at the time of diagnosis [17]. Mocetinostat (MGCD0103), an HDAC1/HDAC2 inhibitor, is found to target Gli1 acetylation to truncate $\mathrm{SHH}$ signaling in medulloblastoma cells [18]. Recently, from a 960-compound screening, quisinostat and other class I HDAC inhibitors are found to suppress growth of diverse $\mathrm{SHH}$ signaling inhibitorresistant clones of mouse medulloblastoma cells [19]. For group 3 medulloblastoma, Wechsler-Reya and colleagues have screened 3642 compounds using mouse medulloblastoma cells [20]. They found that HDAC inhibitors were among the agents that inhibited growth of medulloblastoma tumor cells at submicromolar concentrations. Importantly, HDAC inhibitors and PI3K inhibitors cooperate to inhibit the growth of c-Myc-driven mouse medulloblastoma and human patient-derived xenograft tumors [20].

In this study, we employed Daoy cells, a human medulloblastoma cell line resembling the SHH subtype [21], and screened 12,800 compounds for their antimedulloblastoma activity. We found 46 compounds that inhibited Daoy cell growth in a dose-responsive manner with an $\mathrm{IC}_{50}$ of $\leq 1.0 \mu \mathrm{M}$ for $48 \mathrm{~h}$. In addition, we used D283 cells, a long-established cell line that represents an intermediate subtype between Group 3 and 4 medulloblastoma [21], to further analyze the efficacy of selected compounds. D283 cells show MYC overexpression at the mRNA and protein level and exhibit OTX2 overexpression consistent with Group 3 and 4 [21]. Two compounds, quisinostat and dacinostat (both HDAC inhibitors), significantly inhibited the viability of both Daoy and D238 at submicromolar concentrations. Dacinostat (also known as LAQ824), is a panHDAC inhibitor belonging to a class of hydroxamic acid analogs known to inhibit class I, IIa, and IIb histone deacetylases [22, 23]. It has been tested in animal models for its direct antitumor effects, mainly against hematopoietic lineage cancer cells [22, 24-26], but also against various types of solid tumors, such as lung, colon, and prostatic cancers [27-29]. Quisinostat (also known as JNJ26481585), is a second generation panHDAC inhibitor. It is effective against several tumor types, including colon cancer [30], glioblastoma [31], leukemia [32], and multiple myeloma [33, 34]. To date, four HDAC inhibitors (panobinostat, romidepsin, heliostat, and vorinostat) have been approved by the United States Food and Drug Administration for the treatment of hematological malignancies, such as cutaneous T-cell lymphoma, peripheral T-cell lymphoma, and multiple myeloma [35-39].

HDACs catalyze the removal of acetyl groups from lysine residues of nuclear histones as well as cytoplasmic substrates, and HDAC inhibition affects diverse cellular processes including cell cycle control and apoptosis [40-43]. We demonstrated that both dacinostat and quisinostat induce cell apoptosis and G2/M arrest in medulloblastoma. Daoy and D283 cells and attenuate xenograft tumorigenesis in immunodeficient mice. Dacinostat and quisinostat exercise their anti-medulloblastoma activity via induction of caspase- 3 and PARP cleavage and augmenting the acetylation for histones $\mathrm{H} 3$ and H4. Further studies using more cell lines and the orthotopic model will help to move HDAC inhibitors into clinical care for medulloblastoma patients. As Daoy and D283 cells represent different medulloblastoma subtypes, these data support dacinostat and quisinostat as potential drug candidates for broad medulloblastoma therapy.

\section{Conclusions}

Our work shows that dacinostat and quisinostat exhibit effective anti-tumor activity for two different medulloblastoma subtypes in vitro and medulloblastoma mouse xenografts in vivo. Our data call for new clinical trials to evaluate the efficacy of dacinostat, quisinostat, and other HDAC inhibitors, against medulloblastoma.

\section{Supplementary information}

Supplementary information accompanies this paper at https://doi. org/10.1186/s40164-019-0153-x.

Additional file 1: Data S1. Dose response curves of Daoy cells treated with 125 compounds.

Additional file 2: Figure S1. Compound activity and plate Z'-factor for the primary screening. (A) Compound activity distribution. Blue dots (Inhibitor Control): positive control group (10 $\mu \mathrm{M}$ staurosporine, 100\% inhibition); black dots (Neutral Control): negative control group (DMSO group, $0 \%$ inhibition); yellow dots (Hit Compound): primary hits (hit compound) (125 compounds that displayed $\geq 90 \%$ inhibition chosen for a dose-response analysis); grey dots (Compound): compounds not chosen for further confirmation (\% inhibition <90\%). Y-axis: \% Activity is assessed as the percentage of viability inhibited. The activity from 12,800 library compounds and control compounds in each plate were shown. (B) Z'-factor calculated for each plate. (C) The dose response curves for cell viability of Daoy cells. Ten concentrations, 1:3 serially diluted ranging from 50 to $0.0025 \mu \mathrm{M}$, were used in triplicate.

\section{Abbreviations}

HDAC: histone deacetylase; FDA: Food and Drug Administration; DMSO: dimethyl sulfoxide; PBS: phosphate-buffered saline; ATCC: American Type Culture Collection; NIH: National Institutes of Health; PI: propidium iodide; NSG: NOD scid gamma; WNT: wingless-related integration site; $\mathrm{SHH}$ : sonic hedgehog. 


\section{Acknowledgements}

The authors are grateful to Dr. Cassandra Talerico for editing the manuscript and providing critical comments.

\section{Authors' contributions}

POO and TC designed the high throughput screening (HTS). POO performed the screen. POO and DGC analyzed the screening data. SZ, ZG, and $Y L$ designed the following-up research. All authors performed experiments and/or contributed to data analyses, SZ, ZG, POO, DGC, TC and YL wrote the manuscript, and all authors provided critical review and revisions. All authors read and approved the final manuscript.

\section{Funding}

The authors are grateful to Dr. Cassandra Talerico for editing the manuscript and providing critical comments. This study was supported by an NIH R01 grant (CA177810 to YL), and by ALSAC and R35GM118041 (to TC). YL is supported in part by a recruitment grant from Cancer Prevention and Research Institute of Texas (RR190043). The Human Tissue Acquisition and Pathology Core is supported by an NCI P30 Center Grant (CA125123).

\section{Availability of data and materials}

All data and materials supporting the conclusion of this study have been included within the article and Additional files.

\section{Ethics approval and consent to participate}

Animal experiments are approved by the Cleveland Clinic Institutional Animal Care and Use Committees. There is no human subject participation.

\section{Consent for publication}

This study does not include any individual person's data in any form.

\section{Competing interests}

The authors declare that they have no competing interests.

\section{Author details}

${ }^{1}$ Section of Epidemiology \& Population Sciences, Department of Medicine, Baylor College of Medicine, Houston, TX, USA. ${ }^{2}$ Department of Cancer Biology, Lerner Research Institute, Cleveland Clinic, Cleveland, OH, USA. ${ }^{3}$ Department of Stomatology, Xiangya Hospital, Central South University, Changsha, China. ${ }^{4}$ Department of Stomatology, The Second Xiangya Hospital, Central South University, Changsha, China. ${ }^{5}$ Department of Chemical Biology and Therapeutics, St. Jude Children's Research Hospital, Memphis, TN, USA. ${ }^{6}$ State Key Laboratory of Respiratory Diseases, Guangzhou Institute of Respiratory Diseases, The First Affiliated Hospital of Guangzhou Medical University, Guangzhou Medical University, Guangzhou, China.

\section{Received: 25 July 2019 Accepted: 4 November 2019}

Published online: 15 November 2019

\section{References}

1. Louis DN, Perry A, Reifenberger G, von Deimling A, Figarella-Branger D, Cavenee WK, Ohgaki H, Wiestler OD, Kleihues P, Ellison DW. The 2016 World Health Organization classification of tumors of the central nervous system: a summary. Acta Neuropathol. 2016;131(6):803-20.

2. Northcott PA, Korshunov A, Witt H, Hielscher T, Eberhart CG, Mack S, Bouffet E, Clifford SC, Hawkins CE, French P, et al. Medulloblastoma comprises four distinct molecular variants. J Clin Oncol. 2011;29(11):1408-14.

3. Northcott PA, Shih DJH, Peacock J, Garzia L, Sorana Morrissy A, Zichner T, Stutz AM, Korshunov A, Reimand J, Schumacher SE, et al. Subgroup-specific structural variation across 1,000 medulloblastoma genomes. Nature. 2012;488(7409):49-56.

4. Pugh TJ, Weeraratne SD, Archer TC, Pomeranz Krummel DA, Auclair D, Bochicchio J, Carneiro MO, Carter SL, Cibulskis K, Erlich RL, et al. Medulloblastoma exome sequencing uncovers subtype-specific somatic mutations. Nature. 2012;488(7409):106-10.

5. Taylor MD, Northcott PA, Korshunov A, Remke M, Cho YJ, Clifford SC, Eberhart CG, Parsons DW, Rutkowski S, Gajjar A, et al. Molecular subgroups of medulloblastoma: the current consensus. Acta Neuropathol. 2012;123(4):465-72
6. Kool M, Korshunov A, Remke M, Jones DT, Schlanstein M, Northcott PA, Cho YJ, Koster J, Schouten-van Meeteren A, van Vuurden D, et al. Molecular subgroups of medulloblastoma: an international meta-analysis of transcriptome, genetic aberrations, and clinical data of WNT, SHH, Group 3, and Group 4 medulloblastomas. Acta Neuropathol. 2012;123(4):473-84

7. Glozak MA, Seto E. Histone deacetylases and cancer. Oncogene. 2007;26(37):5420-32.

8. LiY, Seto E. HDACs and HDAC inhibitors in cancer development and therapy. Cold Spring Harb Perspect Med. 2016;6(10):a026831.

9. Milde T, Oehme I, Korshunov A, Kopp-Schneider A, Remke M, Northcott P, Deubzer HE, Lodrini M, Taylor MD, von Deimling A, et al. HDAC5 and HDAC9 in medulloblastoma: novel markers for risk stratification and role in tumor cell growth. Clin Cancer Res. 2010;16(12):3240-52.

10. Ippagunta SK, Pollock JA, Sharma N, Lin W, Chen T, Tawaratsumida K, High AA, Min J, Chen Y, Guy RK, et al. Identification of Toll-like receptor signaling inhibitors based on selective activation of hierarchically acting signaling proteins. Sci Signal. 2018;11(543):eaaq1077.

11. Lin W, Wu J, Dong H, Bouck D, Zeng FY, Chen T. Cyclin-dependent kinase 2 negatively regulates human pregnane $X$ receptor-mediated CYP3A4 gene expression in HepG2 liver carcinoma cells. J Biol Chem. 2008;283(45):30650-7.

12. Pitre $A, G e Y$, Lin W, Wang $Y$, Fukuda $Y$, Temirov J, Phillips AH, Peters JL, Fan $Y, M a$ J, et al. An unexpected protein interaction promotes drug resistance in leukemia. Nat Commun. 2017;8(1):1547.

13. Lin W, Goktug AN, Wu J, Currier DG, Chen T. High-throughput screening identifies 1,4,5-substituted 1,2,3-triazole analogs as potent and specific antagonists of pregnane $X$ receptor. Assay Drug Dev Technol. 2017;15(8):383-94.

14. Teitz T, Fang J, Goktug AN, Bonga JD, Diao S, Hazlitt RA, Iconaru L, Morfouace M, Currier D, Zhou Y, et al. CDK2 inhibitors as candidate therapeutics for cisplatin- and noise-induced hearing loss. J Exp Med. 2018;215(4):1187-203.

15. Roberts KG, Yang YL, Payne-Turner D, Lin W, Files JK, Dickerson K, Gu Z Taunton J, Janke LJ, Chen T, et al. Oncogenic role and therapeutic targeting of ABL-class and JAK-STAT activating kinase alterations in Ph-like ALL. Blood Adv. 2017;1(20):1657-71.

16. Zhang JH, Chung TD, Oldenburg KR. A simple statistical parameter for use in evaluation and validation of high throughput screening assays. J Biomol Screen. 1999;4(2):67-73.

17. Cho Y-J, Tsherniak A, Tamayo P, Santagata S, Ligon A, Greulich H, Berhoukim R, Amani V, Goumnerova L, Eberhart CG, et al. Integrative genomic analysis of medulloblastoma identifies a molecular subgroup that drives poor clinical outcome. J Clin Oncol. 2011;29(11):1424-30.

18. Coni S, Mancuso AB, Di Magno L, Sdruscia G, Manni S, Serrao SM, Rotili D, Spiombi E, Bufalieri F, Petroni M, et al. Selective targeting of HDAC1/2 elicits anticancer effects through Gli1 acetylation in preclinical models of SHH medulloblastoma. Sci Rep. 2017;7:44079.

19. Pak E, MacKenzie EL, Zhao X, Pazyra-Murphy MF, Park PMC, Wu L, Shaw DL, Addleson EC, Cayer SS, Lopez BG, et al. A large-scale drug screen identifies selective inhibitors of class I HDACs as a potential therapeutic option for SHH medulloblastoma. Neuro Oncol. 2019;21(9):1150-63.

20. Pei Y, Liu KW, Wang J, Garancher A, Tao R, Esparza LA, Maier DL, Udaka YT, Murad N, Morrissy S, et al. HDAC and PI3K antagonists cooperate to inhibit growth of MYC-driven medulloblastoma. Cancer Cell. 2016:29(3):311-23.

21. Ivanov DP, Coyle B, Walker DA, Grabowska AM. In vitro models of medulloblastoma: choosing the right tool for the job. J Biotechnol. 2016;236:10-25.

22. Catley L, Weisberg E, Tai YT, Atadja P, Remiszewski S, Hideshima T, Mitsiades N, Shringarpure R, LeBlanc R, Chauhan D, et al. NVP-LAQ824 is a potent novel histone deacetylase inhibitor with significant activity against multiple myeloma. Blood. 2003;102(7):2615-22

23. Bali P, George P, Cohen P, Tao J, Guo F, Sigua C, Vishvanath A, Scuto A, Annavarapu S, Fiskus W, et al. Superior activity of the combination of histone deacetylase inhibitor LAQ824 and the FLT-3 kinase inhibitor PKC412 against human acute myelogenous leukemia cells with mutant FLT-3. Clin Cancer Res. 2004;10(15):4991-7.

24. Atadja P, Gao L, Kwon P, Trogani N, Walker H, Hsu M, Yeleswarapu L, Chandramouli N, Perez L, Versace R, et al. Selective growth inhibition of tumor cells by a novel histone deacetylase inhibitor, NVP-LAQ824. Cancer Res. 2004;64(2):689-95. 
25. Weisberg E, Catley L, Kujawa J, Atadja P, Remiszewski S, Fuerst P, Cavazza C, Anderson K, Griffin JD. Histone deacetylase inhibitor NVP-LAQ824 has significant activity against myeloid leukemia cells in vitro and in vivo. Leukemia. 2004;18(12):1951-63.

26. Romanski A, Bacic B, Bug G, Pfeifer H, Gul H, Remiszewski S, Hoelzer D, Atadja P, Ruthardt M, Ottmann OG. Use of a novel histone deacetylase inhibitor to induce apoptosis in cell lines of acute lymphoblastic leukemia. Haematologica. 2004;89(4):419-26.

27. de Bono JS, Kristeleit R, Tolcher A, Fong P, Pacey S, Karavasilis V, Mita M, Shaw H, Workman P, Kaye S, et al. Phase I pharmacokinetic and pharmacodynamic study of LAQ824, a hydroxamate histone deacetylase inhibitor with a heat shock protein-90 inhibitory profile, in patients with advanced solid tumors. Clin Cancer Res. 2008;14(20):6663-73.

28. Remiszewski SW, Sambucetti LC, Bair KW, Bontempo J, Cesarz D, Chandramouli N, Chen R, Cheung M, Cornell-Kennon S, Dean K, et al. N-hydroxy-3-phenyl-2-propenamides as novel inhibitors of human histone deacetylase with in vivo antitumor activity: discovery of (2E)-N-hydroxy-3-[4-[[(2-hydroxyethyl)[2-(1H-indol-3-yl)ethyl] amino]methyl]phenyl]-2-propenamide (NVP-LAQ824). J Med Chem. 2003:46(21):4609-24.

29. Qian DZ, Wang X, Kachhap SK, Kato Y, Wei Y, Zhang L, Atadja P, Pili R. The histone deacetylase inhibitor NVP-LAQ824 inhibits angiogenesis and has a greater antitumor effect in combination with the vascular endothelial growth factor receptor tyrosine kinase inhibitor PTK787/ZK222584. Cancer Res. 2004;64(18):6626-34.

30. Arts J, King P, Marien A, Floren W, Belien A, Janssen L, Pilatte I, Roux B, Decrane L, Gilissen R, et al. JNJ-26481585, a novel "second-generation" oral histone deacetylase inhibitor, shows broad-spectrum preclinical antitumoral activity. Clin Cancer Res. 2009:15(22):6841-51.

31. Carol H, Gorlick R, Kolb EA, Morton CL, Manesh DM, Keir ST, Reynolds $\mathrm{CP}$, Kang MH, Maris JM, Wozniak A, et al. Initial testing (stage 1) of the histone deacetylase inhibitor, quisinostat (JNJ-26481585), by the pediatric preclinical testing program. Pediatr Blood Cancer. 2014;61(2):245-52.

32. Tong WG, Wei Y, Stevenson W, Kuang SQ, Fang Z, Zhang M, Arts J, GarciaManero G. Preclinical antileukemia activity of JNJ-26481585, a potent second-generation histone deacetylase inhibitor. Leuk Res. 2010;34(2):221-8.

33. Stuhmer T, Arts J, Chatterjee M, Borawski J, Wolff A, King P, Einsele H, Leo E, Bargou RC. Preclinical anti-myeloma activity of the novel HDAC-inhibitor JNJ-26481585. Br J Haematol. 2010;149(4):529-36.
34. Deleu S, Lemaire M, Arts J, Menu E, Van Valckenborgh E, King P, Vande Broek I, De Raeve H, Van Camp B, Croucher P, et al. The effects of JNJ26481585, a novel hydroxamate-based histone deacetylase inhibitor, on the development of multiple myeloma in the 5T2MM and 5T33MM murine models. Leukemia. 2009;23(10):1894-903.

35. Bates SE, Eisch R, Ling A, Rosing D, Turner M, Pittaluga S, Prince HM, Kirschbaum MH, Allen SL, Zain J, et al. Romidepsin in peripheral and cutaneous T-cell lymphoma: mechanistic implications from clinical and correlative data. Br J Haematol. 2015;170(1):96-109.

36. Cheng T, Grasse L, Shah J, Chandra J. Panobinostat, a pan-histone deacetylase inhibitor: rationale for and application to treatment of multiple myeloma. Drugs Today. 2015;51(8):491-504.

37. Mann BS, Johnson JR, Cohen MH, Justice R, Pazdur R. FDA approval summary: vorinostat for treatment of advanced primary cutaneous T-cell lymphoma. Oncologist. 2007;12(10):1247-52.

38. O'Connor OA, Horwitz S, Masszi T, Van Hoof A, Brown P, Doorduijn J, Hess G, Jurczak W, Knoblauch P, Chawla S, et al. Belinostat in patients with relapsed or refractory peripheral T-cell lymphoma: results of the pivotal phase II BELIEF (CLN-19) Study. J Clin Oncol. 2015;33(23):2492-9.

39. Shi Y, Dong M, Hong X, Zhang W, Feng J, Zhu J, Yu L, Ke X, Huang H, Shen $Z$, et al. Results from a multicenter, open-label, pivotal phase II study of chidamide in relapsed or refractory peripheral T-cell lymphoma. Ann Oncol. 2015;26(8):1766-71.

40. de Ruijter AJ, van Gennip AH, Caron HN, Kemp S, van Kuilenburg AB. Histone deacetylases (HDACs): characterization of the classical HDAC family. Biochem J. 2003;370(Pt 3):737-49.

41. Kim MS, Kwon HJ, Lee YM, Baek JH, Jang JE, Lee SW, Moon EJ, Kim HS, Lee $\mathrm{SK}$, Chung HY, et al. Histone deacetylases induce angiogenesis by negative regulation of tumor suppressor genes. Nat Med. 2001;7(4):437-43.

42. Li Z, Zhu WG. Targeting histone deacetylases for cancer therapy: from molecular mechanisms to clinical implications. Int J Biol Sci. 2014;10(7):757-70.

43. Yang XJ, Seto E. The Rpd3/Hda1 family of lysine deacetylases: from bacteria and yeast to mice and men. Nat Rev Mol Cell Biol. 2008;9(3):206-18.

\section{Publisher's Note}

Springer Nature remains neutral with regard to jurisdictional claims in published maps and institutional affiliations.
Ready to submit your research? Choose BMC and benefit from:

- fast, convenient online submission

- thorough peer review by experienced researchers in your field

- rapid publication on acceptance

- support for research data, including large and complex data types

- gold Open Access which fosters wider collaboration and increased citations

- maximum visibility for your research: over $100 \mathrm{M}$ website views per year

At BMC, research is always in progress.

Learn more biomedcentral.com/submissions 